\section{A New U.S.-U.S.S.R. Seismological Program}

J. Berger,1 J. N. Brune,1 P. A. Bodin,1 J. S. Gomberg,1 D. M. Carrel, ${ }^{1}$ K. F. Priestley, ${ }^{2}$ D. E. Chavez, ${ }^{2}$ W. R. Walter, ${ }^{2}$ C. B. Archambeau, ${ }^{3}$ T. B. Cochran, ${ }^{4}$ I. L. Nersesov, ${ }^{5}$ M. B. Gokhberg, ${ }^{5}$ O. A. Stolyrov, 5 S. K. Daragen, ${ }^{5}$ N. D. Tarassov, ${ }^{5}$ and Y. A. Sutelov 5

\section{PAGES 105, 110-111}

\section{Introduction}

On July 9, 1986, a team of researchers from the University of California, San Diego University of Nevada, Reno; and the University of Colorado, Boulder established the first of three seismic stations to be located in the vicinity of the Soviet nuclear test site in eastern Kazakhstan (KTS) (see cover). Under an agreement reached between the Soviet Academy of Sciences and the Natural Resources Defense Council, a nonprofit U.S. environmental organization, these stations, which are configured to meet the specifications of the proposed new global seismographic network [Incorporated Research Institutions for Seismology (IRIS), 1984], will be complemented by three similarly equipped stations to be installed in the vicinity of the U.S. nuclear test site in southern Nevada (NTS). The stations are to be operated cooperatively by Soviet and U.S. personnel

(Figure 1)

The data that are collected by this joint program are meant to be relevant to several seismological problems associated with the monitoring and verification of present and future test ban treaties. These include

- Determination of ambient ground noise levels as a function of frequency and time. The noise levels obviously control the magnitude

${ }^{1}$ Institute of Geophysics and Planetary Physics, Scripps Institution of Oceanography, University of California, San Diego, La Jolla

${ }^{2}$ University of Nevada, Mackay School of Mines, Reno

${ }^{3}$ Cooperative Institute for Research in Environmental Science, University of Colorado, Boulder

${ }^{4}$ Natural Resources Defense Council, Washington, D.C.

${ }^{5}$ Institute of Physics of the Earth, Academy of Sciences of the Soviet Union, Moscow

Cover. Locations of three Kazakh seismic stations in the Soviet Union that were established by teams of U.S. researchers from the University of California (San Diego), University of Nevada (Reno), and University of Colorado (Boulder). These stations, which will be operated cooperapart of a recent agreement between U.S. and Societ researchers. For more information, see the article "A New U.S.-U.S.S.R. Seismological Program" by J. Berger et al., page 105 . tively by U.S. and Soviei personnel, are of events that can be detected and the accuracy with which they can be characterized by any given station configuration. Initially, portable equipment was used to measure ambient noise on the surface and to locate suitable sites for the installation of more permanent equipment. The data will allow the characterization of the surface ground noise for frequencies in the band $3600 \mathrm{~s}$ to $100 \mathrm{~Hz}$ and will determine the signal-to-noise improvement over the $1-100-\mathrm{Hz}$ band achieved through the use of 100-m-deep boreholes.
- Examination of the excitation of regional phases, including $P_{n}, P_{g}, S_{n}, S_{g}, L_{g}$, and $\boldsymbol{R}_{\mathrm{g}}$. The excitation efficiency and spectrum of these phases is important in the determination of source properties of events recorded at regional distances [Evernden et al., 1986]. Numerous studies of these phases the Nevada test site, but the Kazakh network will provide the first opportunity to study these phases in this region and thus reduce uncertainties due to propagation effects.

- Determination of the velocity and attenua tion characteristics of regional phases and surface waves. Studies have been conducted in Nevada [e.g., Chavez and Priestley, 1986] and Marshall et al. [1979] have utilized measurements of the velocity of propagation of $P_{n}$ in the Kazakh region to infer that the upper mantle attenuation is low compared to that in Nevada and is more typical of that in shield areas. It has been suggested by several authors that because of this low attenuation, the yield versus $m_{b}$ relationship for nuclear explosions is considerably different for KTS than it is for NTS [Marshall et al., 1979; Sykes et al., 1983]. This has important bearing on current and future monitoring of the threshhave been carried out for the region around

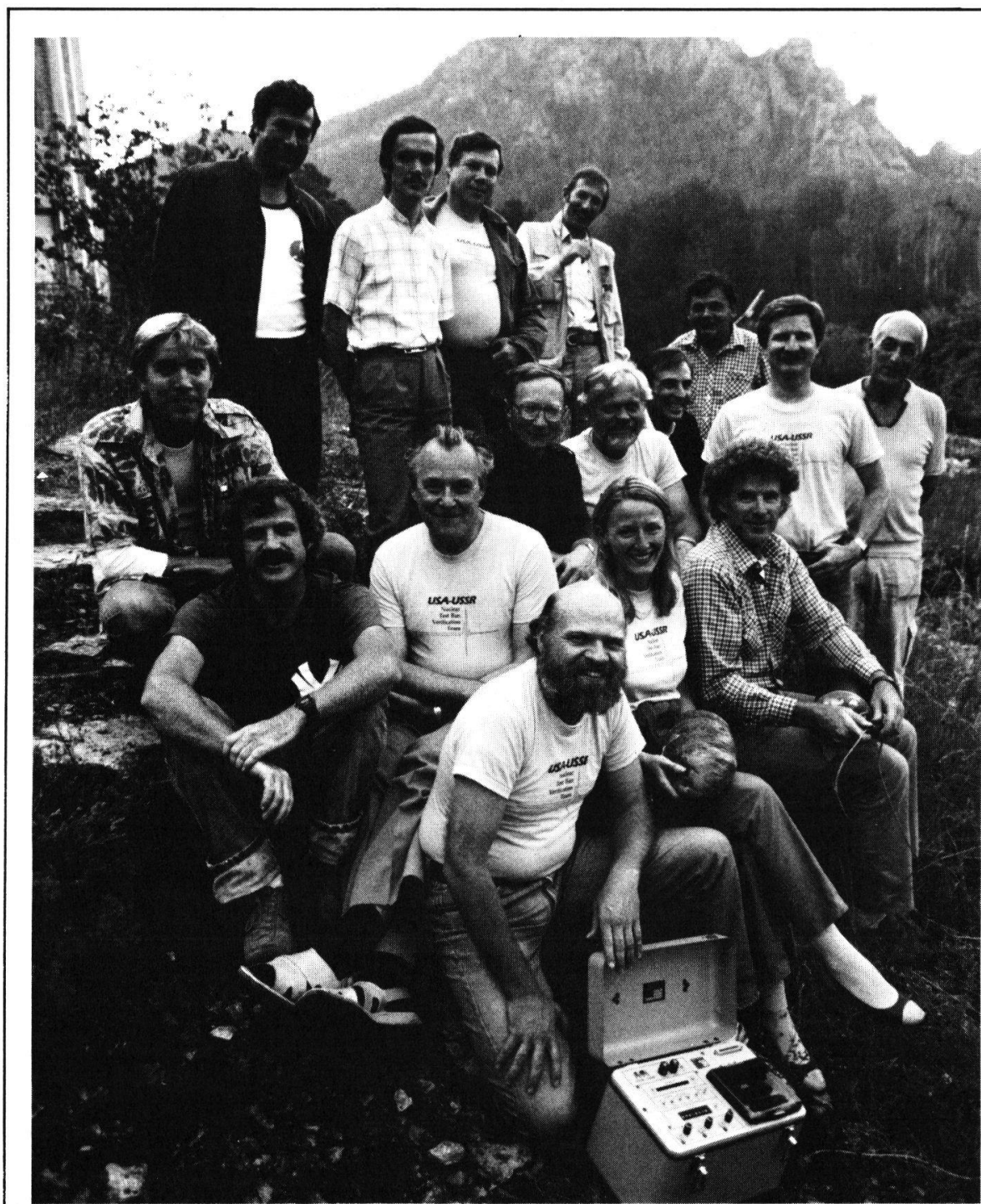

Fig. 1. Members of the U.S.-Soviet seismological team at network headquarters, Karkaralinsk, in eastern Kazakhstan, U.S.S.R. (photograph by Ted Spiegel, Black Star) 


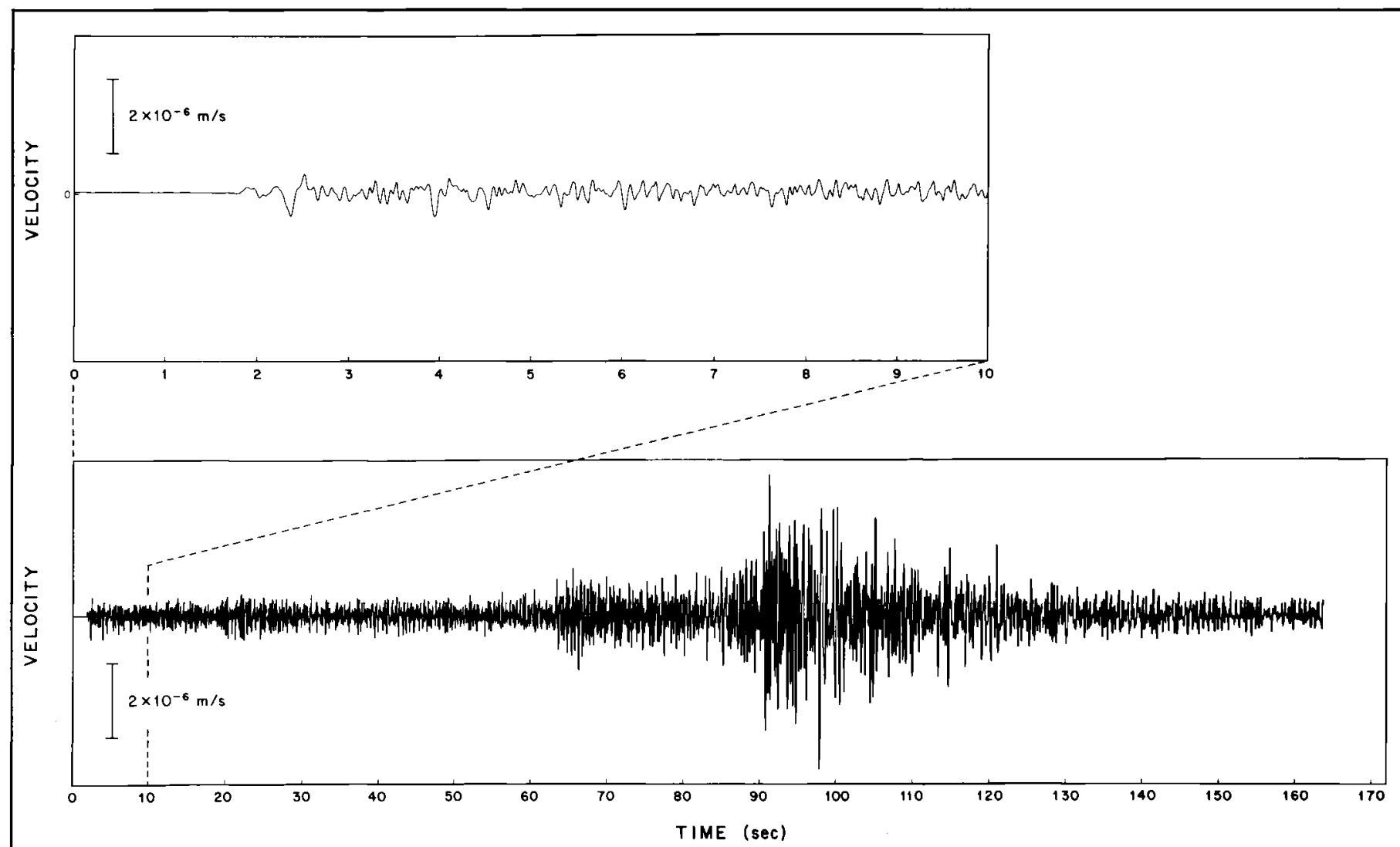

Fig. 2. Recording from Karkaralinsk station of a regional event in southeastern Kazakhstan, $44.5^{\circ} \mathrm{N}, 79.5^{\circ} \mathrm{E}$, on July 21,1986 , at $22: 41: 56$ local time. Source-receiver distance is $626 \mathrm{~km}, m_{b}=4.6$. The first 10 seconds of the event has been expanded to show the clear high frequencies in the $P_{n}$. Spectral analysis if the $P$ wave train indicates energy with good signal-to-noise ratio at least up to the antialiasing filter corner at $30 \mathrm{~Hz}$.

old test ban and has led to considerable controversy.

On the U.S. side, the overall science program is directed by a committee consisting of the following researchers:

- C. B. Archambeau, chairman (Cooperative Institute for Research in Environmental Science, University of Colorado, Boulder),

- S. S. Alexander (Pennsylvania State University, University Park),

- J. Berger (Institute of Geophysics and Planetary Physics (IGPP), Scripps Institution of Oceanography (SIO), University of California, San Diego, La Jolla),

- J. N. Brune (IGPP/SIO),

- D. G. Harkrider (Seismological Laboratory, California Institute of Technology, Pasadena, Calif.),

- D. V. Helmberger, alternate (Seismological Laboratory, California Institute of Technology, Pasadena, Calif.),

- E. T. Herrin (Southern Methodist University, Dallas, Tex.),

- T. H. Jordan (Massachusetts Institute of Technology, Cambridge, Mass.),

- J. B. Minster (Science Horizons, Encintas, Calif.),

- J. R. Murphy (S-Cubed, Reston, Va.),

- R. A. Phinney (Princeton University, Princeton, N.J.),

- P. G. Richards, alternate (Lamont-Doherty Geological Observatory, Palisades, N.Y.),

- S. W. Smith (University of Washington, Seattle),

- G. G. Sorrels (Teledyne/Geotech, Dallas, Tex.),
- L. R. Sykes (Lamont-Doherty Geological Observatory, Palisades, N.Y.).

\section{Program Status}

\section{Soviet Stations}

A two-phase deployment of seismographic equipment in Kazakhstan began in early July. Phase I equipment consisted of Teledyne Geotech S-13 short-period and Kinemetrics S-1 intermediate-period seismometers (Teledyne Geotech, Garland, Texas; Kinemetrics' Systems, Pasadena, Calif.) coupled to Terra Technology 302 event-triggered data loggers sampling at $100 \mathrm{~Hz}$ (Terra Technology, Redmond, Wash.). These were first employed in noise surveys as part of the site selection process. When the station locations had been decided, the Phase I equipment was installed nearby while site preparation was underway for the Phase II equipment. Figure 2 shows a recording obtained early in the project of a regional event to the south, clearly indicating rich high-frequency body wave signals.

Construction of the Phase II Kazakh stations, illustrated in Figure 3, was completed in early November 1986. The sites are all located in granite massifs that rise several hundred meters above the surrounding steppe. Boreholes with diameters of $20 \mathrm{~cm}$ were drilled to depths of 70-100 m, cased, and sealed. Wellhead vaults were set into the surface rocks to a depth of $1.5-2 \mathrm{~m}$ and then covered with soil that was sloped gently to the surrounding terrain to provide both thermal insulation and to reduce wind resistance. The interiors of these vaults measure approxi-

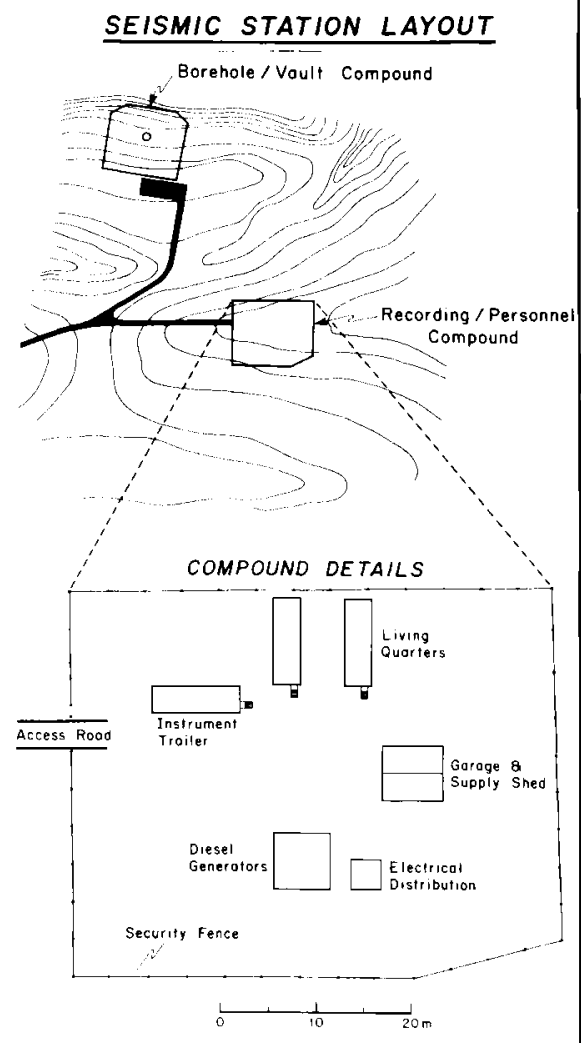

Fig. 3. Layout of the Kazakh station physical plant. 
Eos, Vol. 68, No. 8, February 24, 1987

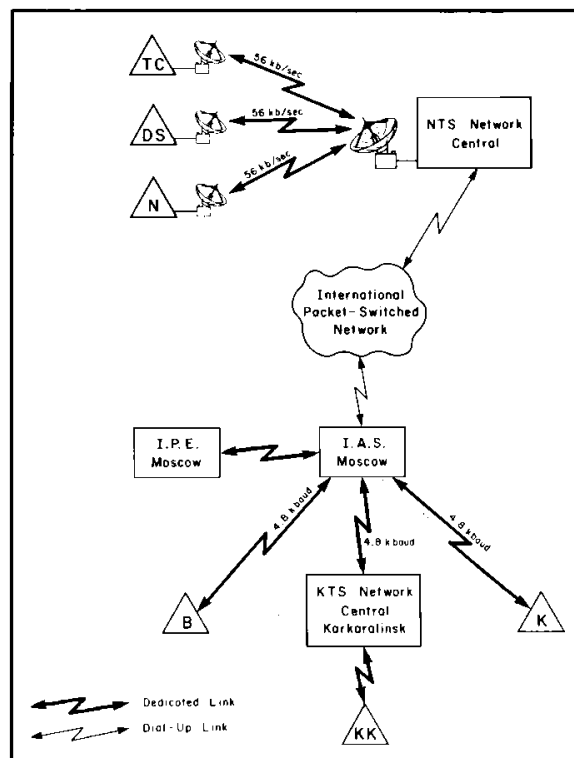

Fig. 4. Telemetry system and internetwork link for the Soviet and U.S. networks. IPE is the Institute of Physics of the Earth, and IAS is the Institute for Automated Systems.

mately $3 \times 4 \mathrm{~m}$, with a $1.2 \times 2-\mathrm{m}$ instrument pier situated next to the top of the borehole. Two trailers at each site provide accommodation for the Soviet personnel who will man the stations continuously and for occasionally visiting American personnel, who will be stationed at network headquarters at Karkaralinsk. A third trailer will house the recording and other instruments. High-voltage power lines have been led to each site, but because of the remoteness and climatic conditions, backup diesel generators have also been in stalled.

Table 1 lists the Phase II complement of equipment that is to be installed at the $\mathrm{Ka}$ zakh sites. High-frequency accelerometers emplaced in the boreholes will be augmented by short-period and broadband seismometers installed in the wellhead vault. Digitization and data recording equipment will be similar to that currently operational in the Anza Network in southern California [Berger et al., 19831; data channels will be sampled at 250 $\mathrm{Hz}$, with a 16-bit resolution. For both the short-period and broadband seismometers, high- and low-gain channels will be recorded to increase the dynamic range. Data will be telemetered from the wellhead vault to the recording trailer via a wireline. The equipment is designed to cover the seismic spectrum between $3600 \mathrm{~s}$ and $100 \mathrm{~Hz}$, with resolution and system noise adequate to allow the measurement of ambient ground noise.

At each station, the MA-II data acquisition system (fabricated at IGPP by the U.S. team) will reduce the raw data rate of approximately $6 \mathrm{~KB} / \mathrm{s}$ (kilobytes per second) to an average of about $75 \mathrm{~B} / \mathrm{s}$ to $225 \mathrm{~B} / \mathrm{s}$ by event detection and decimation to a $2-\mathrm{Hz}$ sampling rate in the case of the continuously recorded broadband data streams. The data will be recorded locally on magnetic tape and forwarded to network central, which is located some $10 \mathrm{~km}$ from the Karkaralinsk station.

In a cooperative project with the Institute for Automated Systems (IAS) in Moscow, the three Kazakh stations will be linked together

TABLE 1. Major Equipment Complement of Kazakh Stations

\begin{tabular}{|c|c|c|c|}
\hline Item & Model & Quantity & Manufacturer \\
\hline Borehole seismometer & 54100 & 1 & $\begin{array}{l}\text { Teledyne Geotech, } \\
\text { Garland, Tex. }\end{array}$ \\
\hline Short-period seismometer & GS-13 & 3 & $\begin{array}{l}\text { Teledyne Geotech, } \\
\text { Garland, Tex. }\end{array}$ \\
\hline $\begin{array}{l}\text { Intermediate-period } \\
\text { seismometer }\end{array}$ & S- 1 & 3 & $\begin{array}{l}\text { Kinemetrics/Systems, } \\
\text { Pasadena, Calif. }\end{array}$ \\
\hline Broadband seismometer & STS-VBB & 3 & $\begin{array}{l}\text { Gunar Streckeisen, } \\
\text { Pfungen, Switzerland }\end{array}$ \\
\hline Remote digitizer & $\mathrm{RT}-24 \mathrm{~A}$ & 5 & $\begin{array}{l}\text { Refraction Technology, } \\
\text { Inc., Dallas, Tex. }\end{array}$ \\
\hline Remote interface unit & RT $-44 \mathrm{~B}$ & 1 & $\begin{array}{l}\text { Refraction Technology, } \\
\text { Inc., Dallas, Tex. }\end{array}$ \\
\hline Data acquisition system & MA-II & 1 & $\begin{array}{l}\text { University of } \\
\text { California, San Diego }\end{array}$ \\
\hline
\end{tabular}

TABLE 2. Major Equipment Complement at the U.S. Stations

\begin{tabular}{|c|c|c|c|}
\hline Item & Model & Quantity & Manufacturer \\
\hline Borehole seismometer & 54100 & 1 & $\begin{array}{l}\text { Teledyne Geotech, } \\
\text { Garland, Tex. }\end{array}$ \\
\hline Short-period seismometer & GS-13 & 3 & $\begin{array}{l}\text { Teledyne Geotech, } \\
\text { Garland, Tex. }\end{array}$ \\
\hline $\begin{array}{l}\text { Intermediate-period } \\
\text { seismometer }\end{array}$ & S-1 & 3 & $\begin{array}{l}\text { Kinemetrics/Systems, } \\
\text { Pasadena, Calif. }\end{array}$ \\
\hline Broadband seismometer & STS-VBB & 3 & $\begin{array}{l}\text { Gunar Streckeisen, } \\
\text { Pfungen, Switzerland }\end{array}$ \\
\hline Remote digitizer & RT -97 & 1 & $\begin{array}{l}\text { Refraction Technology, } \\
\text { Inc., Dallas, Tex. }\end{array}$ \\
\hline Earth station & Gemini-56 & 1 & $\mathrm{M} / \mathrm{A} \mathrm{COM}$ \\
\hline
\end{tabular}

via 4.8-Kbaud dedicated land lines, as shown in Figure 4. Data from the Bayanaul and Karasu stations will be routed through the IAS facilities to network central in Karkaralinsk. A direct line will bring the data from the Karkaralinsk station to network central The telemetry system, however, is designed to permit the collection of all data on computers at IAS and to provide access to them by scientists at the Institute of Physics of the Earth (IPE) in Moscow.

\section{U.S. Stations}

Sites for the U.S. stations have been chosen at Deep Springs, Calif., and Nelson and Troy Canyon, Nev. Continuous data from this network will be telemetered via $56-\mathrm{Kb} / \mathrm{s}$ satellite circuits from the stations to network central, as illustrated in Figure 5. Major equipment items to be installed in the U.S. stations are listed in Table 2 and differ from those in the Soviet Union only in that the event detection function of the data acquisition system is performed at network central rather than at the individual stations. Operations of the U.S. stations are scheduled to begin in March or April 1987.

Internet connections between the U.S. and Soviet networks will be provided initially by one of the international packet-switched carriers, linking computers in La Jolla, Calif., with those at the IAS in Moscow. This internet service is designed primarily to provide limited data exchange between the two networks and to provide direct message communication between the network centers and remote stations. Experiments with more complete near-real-time data exchange are being planned.

\section{Acknowledgments}

A special acknowledgment is due to $\mathbf{E}$. $\mathbf{P}$. Velikhov, vice president of the Soviet Acade- mv of Sciences, and M. A. Sadovsky, director of the Institute of Physics of the Earth, for their leadership in arranging this cooperative project. Implementation of this project has been greatly assisted by Adrian N. DeWind, chairman of the board, John A. Adams, executive director, $\mathbf{S}$. Jacob Scherr, senior attorney, and the staff of the Natural Resources Defense Council.

Major funding for the U.S. part of this project has been provided by the John $\mathrm{D}$. and Catherine T. MacArthur Foundation, the Carnegie Corporation of New York, Ploughshares Fund, the W. Alton Jones Foundation, J. M. Kaplan Fund, the Columbia Foundation, and an anonymous donor.

\section{References}

Berger, J., L. N. Baker, J. N. Brune, J. B. Fletcher, T. C. Hanks, and F. L. Vernon, The Anza array: A high dynamic-range, broad-band, digitally recorded, radio-telemetered seismic array, Bull. Seismol. Soc. Am., 74, 1469, 1984.

Chavez, D., and K. F. Priestley, Measurements of frequency dependent $L_{g}$ attenuation in the Great Basin, Geophys. Res. Lett., $13,551,1986$.

Dahlman, O., and H. Israclson, Monitoring Underground Nuclear Explosions, Elsevier, New York, 1977.

Evernden, J. F., C. B. Archambeau, and E. Cranswick, An evaluation of seismic decoupling and underground nuclear test monitoring using high-frequency seismic data, Rev. Geophys., 24, 143, 1986.

Incorporated Research Institutions for Seismology (IRIS), Science plan for a new global seismographic network, report, Washington, D.C., 1984.

Marshall, P. D., D. L. Springer, and H. C. Rodean, Magnitude corrections for attenu- 
ation in the upper mantle, Geophys. J. R. Astron. Soc., 57, 609, 1979.

Savino, J. M., C. B. Archambeau, and J. F. Masso, Discrimination results from a 10 . station network, Rep. SSS-CR-79-4566, S-
Cubed, La Jolla, Calif., 1980

Sykes, J. M., J. F. Evernden, and I. Cifuentes, Seismic methods for verifying nuclear test bans, Conf. Proc. 104, Am. Inst. Phys., New York, 1983.

\section{The Case for Planetary Sample Return Missions:}

\section{Origin of the Solar System}

PAGES 105, 111-113

\section{Michael J. Drake and William V. Boynton \\ Lunar and Planetary Laboratory, University of Arizona, Tucson}

\section{Douglas P. Blanchard \\ NASA Johnson Space Center, Houston, Tex}

The "flyby" phase of solar system exploration will be completed for all planetary objects except Pluto and the asteroids by the end of this decade. By the end of the century, the moon and all of the terrestrial planets except Mercury will have been examined by orbiting global remote sensing spacecraft, and Venus, the moon, and Mars have already had in situ surface analyses performed by landers. Samples have been returned only from the moon. Sample returns from both primitive and evolved bodies are essential if we are to understand the origin and evolution of the solar system. Here we examine how measurements made in terrestrial laboratories on samples returned from Venus, Mars, comets, and asteroids can provide information about the formation of the solar system. Feasible approaches for returning samples from these bodies are outlined. Sample return missions may not occur before the 21 st century, but it is necessary to plan them now.

Editor's Note: The following article is part of a series of articles.

\section{Introduction}

Human beings have studied the cosmos for probably as long as we have existed as a species. The earliest written records and the oral traditions of cultures that lack writing bear testament to our curiosity about our place in the universe, no matter how dimly perceived that "universe" might have been. The development of technology has permitted us to study our surroundings by using instruments to enhance our native senses. Now, gradually, we are reaching out into our solar system with space vehicles and are probing to the edge of the universe, using telescopes to col lect radiation emitted long ago from almost unimaginably distant sources.

A driving question in our study of the cos- mos is the place occupied within it by our own solar system. Inexorably intertwined with this question is the origin of the solar system and its subsequent evolution. The study of the solar system, once the realm of the astronomer alone, has now become a multidisciplinary endeavor that also involves geologists, chemists, and physicists. In addition, it has been recognized that solid matter in the solar system (for instance, rocks and ices) collectively retains key memories of the physical and chemical processes that ultimate ly resulted in our own existence.

It has been recognized for nearly 200 years that the earth has been a passive collector of rocks from space, but systematic study of what natural space debris can tell us about the origin and evolution of the solar system and its constituent objects only began in the 1950s. Until recently, all meteorites were believed to be samples of small solar system bodies, such as asteroids and comets, al- though the correlation of any one class of meteorites with a specific body remains, in general, unproven. Although the earth passed through the wake of Comet Halley in 1910 , it was only in the 1970 s that systematic collection and study of stratospheric dust particles, some of which are almost certainly cometary debris, was initiated. The only extraterrestrial samples whose source planet is known unequivocally are samples returned by the manned Apollo and unmanned Luna space missions.

The conclusion that all meteorites are samples of small planetary bodies changed fundamentally in 1983 with the recognition that pieces of the earth's moon could be ejected intact during a meteorite impact and subsequently swept up by the earth (see the special section "A Meteorite From the Moon," a special section in Geophysical Research Letters, vol. 10 , no. 9,1983 ). If meteorites could originate on a body as large as the moon, why should some not also come from Mars? Detailed study of a rare class of meteorites, the shergottites, nakhlites, and Chassigny (or SNC meteorites), now strongly points to an origin on Mars [e.g., Bogard and Johnson, 1983;

McSween, 1985].

Because we now have some knowledge of the characteristics of both small, primitive bodies and of larger, more evolved bodies, we can show that the return of samples from extraterrestrial bodies of known astronomical location will help answer the fundamental question implied in the title of this article, that of the origin of the solar system. In the following sections, we shall argue that sample returns from primitive bodies such as comets and undifferentiated asteroids will provide information concerning the nature of the matter and of the processes that led from the collapse of a cold interstellar dust cloud to the production of small bodies of solid matter. We shall argue that sample returns from large, evolved bodies will provide a record of the composition of the solar system at different heliocentric distances and of the nature of the processes that led to the accretion of small objects of the type preserved as comets and asteroids into large planetary bodies.

\section{Advantages of Measurements on Returned Samples}

Before considering the scientific advantages of sample return missions from different bodies, it is worth considering the advantage of sample return studies over in situ measurements. Our experience with lunar samples and meteorites shows that there are several advantages associated with having a specimen available in the laboratory for study.

First, a much wider range of state-of-theart analytical techniques with higher sensitivities and accuracies can be applied. Many of the scientific problems that researchers would like to address require measurements that are well beyond the current or anticipated capabilities of in situ investigations; indeed, they are well beyond current laboratory-based instruments. A properly curated returned sample is available for reanalysis with new generations and types of instruments. Second, a single sample can be documented and studied by a variety of techniques, allowing all of the data to be related in a way that provides much more scientific insight than the sum of 